\title{
El espacio del pensar de Baltasar Gracián.
}

Sobre la fascinación de una concreción fría

\author{
$\approx$ \\ The Thought Space of Baltasar Gracián. \\ On the Fascination of a Cold Concretion
}

\author{
Hans UlRICH Gumbrecht \\ Universidad de Stanford \\ Estados Unidos \\ Correo: sepp@stanford.edu \\ DOI: 10.48/02/hyg.vi57.384
}

Artículo recibido: 23/I I/2020

Artículo aceptado: 3/02/202I

\section{Abstract}

Baltasar Gracián impressed posterity as a striking profile figure, between whose work and life circumstances there was a formative and illuminating relationship. Scholars who have studied it emphasized above all specific aspects: for example, its place in the tradition of intellectual history, individual philological problems that are difficult to solve, or moments of particular intensity in the history of reception. Thus, in the end, the outline of his signature figure is not filled with a coloring that completes it as an individual image.

Werner Krauss, author of The Doctrine of Life According to Baltasar Gracián, a book about the Jesuit Gracián, puts the Oráculo manual at its center, published in 1647. Gracián's "doctrine of life”, according to Krauss himself, is based in the saving power that rational premises and arguments provide in precarious life situations, and the existential orientation thus acquired becomes independent of the specific circumstances from which it originated. This still holds true for the middle of the 20th Century.

Keywords: Concretion, Baltasar Gracián, Oráculo manual, Doctrine of Life. 


\section{RESUMEN}

Baltasar Gracián impresionó a la posteridad como una figura de perfil llamativo, entre cuya obra y circunstancias de vida existía una relación formativa y esclarecedora. Los eruditos que lo han estudiado pusieron de relieve sobre todo aspectos específicos: por ejemplo, su lugar en la tradición de la historia intelectual, problemas filológicos individuales de difícil resolución, o momentos de particular intensidad en la historia de la recepción. Así, al final, el contorno de su figura de autor no se llena de una coloración que la complete como una imagen individual.

Werner Krauss, autor de La doctrina de la vida según Baltasar Gracián, un libro sobre el jesuita Gracián, pone en su centro el Oráculo manual, publicada en 1647. La "doctrina de la vida” de Gracián, según el propio Krauss, se sustenta en el poder salvador que las premisas y los argumentos racionales proporcionan en precarias situaciones vitales, y la orientación existencial así adquirida se independiza de las circunstancias específicas de las que originó. Esto todavía sigue siendo válido para la mitad del siglo xx.

Palabras clave: concreción, Baltasar Gracián, Oráculo manual, doctrina de vida.

\section{A 1 igual que los demás autores clásicos del "Siglo de Oro" Adesde finales del xvi hasta mediados del xvir, al igual que Miguel de Cervantes, Félix Lope de Vega, Pedro Calderón de la Barca o Luis de Góngora, también el jesuita, predicador y teólogo Baltasar Gracián impresionó a la posteridad como una figura de perfil llamativo, entre cuya obra y circunstancias de vida existía una relación no sólo mutualmente formativa sino también escla- recedora. Pero, a diferencia de sus grandes contemporáneos, y aunque en particular los textos de Gracián pueden parecer muy homogéneos en cuanto a género y contenido, los eruditos que lo han estudiado pusieron de relieve sobre todo aspectos específicos: por ejemplo, su lugar en la tradición de la historia intelectual, problemas filológicos individuales de difícil resolución, o mo- mentos de particular intensidad en la historia de la recepción.}


Así, al final, el contorno de su figura de autor no se llena de una coloración que la complete como una imagen individual.

Esto aplica con una excepción monumental (tanto con respecto a su origen como a lo que resultó de ella): el libro del hispanista alemán Werner Krauss ${ }^{1}$ Graciáns Lebenslehre (La doctrina de la vida según Baltasar Gracián), publicado por primera vez en 1947. En su inicio se encuentra una "nota preliminar", lacónica a más no poder, que por varias razones vale la pena citar en su totalidad:

Este trabajo fue escrito en 1943 en condiciones especiales. El autor consultó las ediciones de Baltasar Gracián que amablemente fueron puestas a su disposición, pero no pudo hacerse de bibliografia secundaria. Si, después de la liberación de Alemania, no se llevó a cabo la correspondiente revisión, ello fué debido a que se ha estimado que una exposición de la doctrina de Gracián, aun sin una exacta coordinación histórico-filológica, reviste de todas formas un interés general. ${ }^{2}$

Con la referencia a las "circunstancias especiales" bajo las cuales se realizó su obra sobre Baltasar Gracián, Krauss aludió en un tono casi incidental a un periodo de veinte meses de detención pasados en el corredor de la muerte de la prisión berlinesa de Plötzensee entre enero de 1943 y septiembre de 1944. Nacido en 1900, había estudiado de 1922 a 1926 en Madrid, luego se doctoró en Múnich bajo la dirección de Karl Vossler con una tesis "La vida cotidiana y la literatura en la Edad Media española", antes de trabajar en los años treinta como asistente del destacado romanista judío Erich Auerbach en la Universidad de Marburgo. Comenzando la Segunda Guerra Mundial, Krauss fue enviado a una compañía de traductores en Berlín. A finales de 1942 fue

\footnotetext{
${ }^{1}$ Publicado en el original por Vittorio Klostermann Verlag (Fráncfort del Meno) y citado aquí según la traducción de Ricardo Estarriol, Madrid, Ed. Rialp, 1962. ${ }^{2}$ Ibidem, p. 15.
} 
arrestado por actividades de propaganda antinazi y, junto con su amante Ursula Götze, dieciséis años más joven, condenado a muerte. Mientras que los dirigentes alemanes decapitaron a Ursula en agosto de 1943, Krauss sobrevivió gracias a la intervención de colegas prominentes, que consiguieron que la primera decisión fuera conmutada por una sentencia de cinco años de prisión. Terminada la guerra, en la República Democrática Alemana se instituyó su significativo trabajo académico, especialmente sobre la Ilustración francesa, como un acervo cultural de poder normativo.

¿Cómo se explica la decisión de Werner Krauss de escribir -frente a la muerte- (además de una novela satírica en clave, titulada Las pasiones de un alma de alción y también publicada después de 1945) un libro sobre el jesuita Gracián, ${ }^{3}$ poniendo en su centro el Oráculo manual, publicada en 1647? Ya la última frase de su "nota preliminar", aunque en un primer momento suene inocua en términos existenciales debido a su tono bastante académico y complicado, señala una respuesta. La "doctrina de la vida” de Gracián, según el alegato de Krauss, se sustenta con tanta prioridad en el poder salvador que las premisas y los argumentos racionales proporcionan en precarias situaciones vitales, que la así adquirida orientación existencial se independiza de las circunstancias específicas de las que originó. Esto todavía sigue siendo válido para la mitad del siglo xx, como se enfatiza en el pasaje final de su libro:

Gracián hubiera podido ser considerado, desde cierto punto de vista, como un precursor de la moderna psicología. Pero su imagen del mundo responde por naturaleza a una orientación muy distinta, cuando no opuesta, a la de aquélla. Mientras que

\footnotetext{
${ }^{3}$ Entre los alumnos de Krauss corría el rumor de que había escrito "con esposas”. Él mismo dejó sin respuesta y sin más comentarios las preguntas sobre sus actividades antinazis, sobre su encarcelamiento, y también sobre su estancia en Espańa durante los años veinte.
} 
la moderna psicología se mueve dentro de la corriente del irracionalismo, el experimento de Gracián -de ampliar y afirmar el autodominio del hombre en el campo del espíritu- parte de la aristocracia del espíritu y nace de una postura preiluminista. [...] la inatacable legitimidad del tipo humano creado por Gracián puede probar que en el campo espiritual los descubrimientos realmente fructíferos no surgen arrogando inconsecuentemente todo el pensamiento heredado de la tradición, sino que nacen al fijar un nuevo objetivo a este enorme poder recibido de los mayores. ${ }^{4}$

Estas frases nos permiten formular una primera hipótesis sobre los orígenes del potencial de fascinación que un texto del siglo XVII ejerce en nuestro presente. Anticipando la Ilustración, como parece suponer Krauss, y partiendo de la emergente posibilidad de descubrir "leyes" abstractas en las formas de vida del "ser humano vinculado a sí mismo", esa época utilizaba la riqueza acumulada de los conocimientos tradicionales en una nueva condensación racional en vez de fiarse a la revelación divina o a la memoria de los valores de la humanidad. Aun visto con independencia completa de los específicos contenidos y formas con los que nos llega el texto de Gracián, éste nos anima a aventurar una autonomía individual (Krauss habla de "autodominio humano") en la conducta de la vida y en las reflexiones que la sustentan. Helmut Lethen ha descrito como "frialdad" (probablemente también en el sentido de "sangre fría") la abstracción distante de esta forma de pensar, y así él explica la fascinación que ella posee para aquellos intelectuales que se encuentran en posiciones extremas. ${ }^{5} \mathrm{El}$ atractivo de tal frialdad de la reflexión, con la que Werner Krauss

\footnotetext{
${ }^{4}$ Ibidem, pp. 297 ss.

${ }^{5}$ Helmut Lethen, Verhaltenslehren der Kälte. Lebensversuche zwischen den Weltkriegen; Id., Suche nach dem Handorakel. Ein Bericht, con referencia a Gracián y Krauss en el capítulo "Vom Finden und dem Verlust des Handorakels", pp. 114-125. Sobre la abstracción y la distancia como tendencias del pensamiento en el entorno histórico de Gracián, cfr. Leonie Pawlita, Staging Doubt. Skepticism in Early Modern European Drama.
} 
sobrevivió en el corredor de la muerte de Plötzensee, puede resultar válido también para nuestra existencia en la vida cotidiana contemporánea con su complejidad por completo diferente. Por el momento tendrá que quedar en suspenso lo que el particular estilo de lenguaje, en el que fueron puestos en papel los términos y argumentos del Oráculo manual, pueda contribuir a ello.

Aquella racionalidad abstracta en el pensamiento de Baltasar Gracián, que es típica para la temprana Modernidad y que chocaba poco con patrones del pensar históricamente específicos de épocas posteriores, por un lado aclara el porqué de una dimensión de durabilidad no-específica en la recepción de sus siete obras. Para todas estas obras, con la excepción del libro devocional religioso El comulgatorio -el único texto publicado bajo su propio nombre durante su vida- una y otra vez se han encontrado lectores, durante casi cuatro siglos. Por otro lado, el Oráculo manual, presentado como una especie de antología de las ideas de Gracián, pronto entró en el primer plano emblemático de su obra y, por diferentes razones bien variadas, ha recibido una resonancia de particular intensidad, sobre todo durante los finales del siglo XVII y luego de nuevo a partir del XIX.

En el contexto europeo más amplio, las obras seculares de Gracián pertenecían a un diverso movimiento de reflexión sobre las estructuras y posibilidades de la acción autónoma y enfocada a fines concretos, lo que quiere decir: ya no formada por la religión. Este movimiento había tenido sus orígenes italianos en $E l$ Cortesano de Baldassare Castiglione en 1528 y en El Príncipe de Nicolás Maquiavelo en 1532, y su continuación durante el Siglo de Oro en España, con una menor orientación específica hacia las figuras principales de la aristocracia y la Corte, ${ }^{6}$ para luego

${ }^{6}$ Cfr. el excelente "Prefacio" de Emilio Blanco a su edición del Oráculo manualy arte de prudencia de Baltasar Gracián, pp. 28 ss. 
culminar, entre los autores del Clasicismo francés como La Bruyère o La Rochefoucauld, en la reflexión -más descriptiva- del "moralismo".

Puede que durante la vida de Gracián y a lo largo de las décadas posteriores a su muerte en diciembre de 1658, haya dominado un uso práctico-político de las huellas que su pensar había legado. El Oráculo manual fue uno de los libros que el rey español Felipe IV consultó con regularidad. ${ }^{7}$ Pero sobre todo la traducción francesa de Amelot de la Housaie bajo el título L'Homme de cour, libremente redactada y parafraseando repetidas veces el texto de Gracián, fue recibida por lectores influyentes en la corte de Versalles de Luis XIV a partir de $1684 .{ }^{8}$ La primera traducción alemana del Oráculo manual del profesor de Leipzig, August Friedrich Müller, publicada entre 1715 y 1719, e hinchando a más de mil quinientos páginas lo que en el original fue un tratado compacto, tenía una orientación similar -aunque al parecer sin contar con el horizonte de referencia concreto de posibles lectores-. ${ }^{9}$

Como el Siglo de las Luces intentó disolver la racionalidad fría de la temprana edad moderna en una moral "general humana”, cuyo discurso desde entonces se ha vuelto normativo para la conciencia política, esta época también marcó con un signo negativo textos como los de Castiglione, Maquiavelo o Gracián. ${ }^{10}$ Pero fue precisamente esta reserva crítica la que sirvió de contraste y motivación para una segunda fase de intensa recepción

${ }^{7}$ Vid. Krauss, La doctrina de la vida según Gracián, p. 17.

${ }^{8}$ Bajo el título "Traduire - De l'Oráculo manual à L'Homme de cour”, Roger Chartier ha elaborado los detalles de esta transferencia, que cambia el potencial funcional del texto de Gracián.

${ }^{9}$ Cfr. Sebastian Neumeister en su "Prólogo" a la nueva edición revisada de la traducción de Schopenhauer del Handorakels und Kunst der Weltklugheit, aquí p. XXV.

${ }^{10}$ Cfr. el sutil análisis de la historia de la recepción de Gracián en Helmut Lethen, Im reißenden Strom der Translationen. Der Gracián-Kick im 20.Jahrhundert, donde describe con amplia documentación e impresionantes matices los casos más importantes de lecturas positivas individuales. 
del Oráculo manual. Hasta el día de hoy forman parte de ella reacciones individuales que derivan en un patetismo particular de la pronunciada oposición a la denominada "moralidad burguesa" -basándose no en una reserva fundamental contra las reivindicaciones morales, sino en un escepticismo frente a las posibilidades de su realización-.

El caso más famoso -no solamente para la cultura alemanade tal reacción ante el calor humano de la Ilustración, es el entusiasmo por Gracián que llevó a Arthur Schopenhauer -quizá además de la precaria situación de sus finanzas- a traducir el Oráculo manual al alemán en el invierno de 1831-1832, en apariencia sólo tres años después de haber aprendido el español. ${ }^{11}$ La nota literaria ("Litterarische Notiz") con la cual se le recomienda al editor Friedrich Fleischer tal vez ocultó dónde radicaba el interés especial del filósofo marcado por el escepticismo y el pesimismo:

El Oráculo manual enseña el arte del cual todos se esfuerzan, y por lo tanto es para todos. Es especialmente adecuado para convertirse en el manual de todos aquellos que viven en el gran mundo, pero sobre todo de los jóvenes que se esfuerzan por hacer su fortuna en él, y que así de pronto y de antemano reciben la enseñanza que de otra manera sólo reciben a través de una larga experiencia. ${ }^{12}$

${ }^{11}$ Sobre las condiciones y consecuencias de esta traducción en la vida de Schopenhauer, vid. David D. Cartwright, Schopenhauer: A Biography, pp. 418422. A diferencia de Neumeister, que escribe sobre los "errores, malentendidos y equivocaciones" de Schopenhauer ("Prólogo", op. cit., p. xxix), considero que la versión de Schopenhauer del Oráculo manual es excelente en cuanto a contenido, aunque con una tendencia (plausible en vista de las dificultades del original) hacia las paráfrasis e interpretaciones implícitas; en algunos lugares se aleja mucho del estilo de pensamiento y escritura de Gracián.

${ }^{12}$ Citado según Neumeister, "Prólogo", op. cit., p. xxvi: "Das Handorakel lehrt die Kunst, deren Alle sich befleißigen, und ist daher für Jedermann. Beonders aber ist es geeignet, das Handbuch all derer zu werden, die in der großen Welt leben, ganz vorzüglich aber junger Leute, die ihr Glück darin zu machen bemüht sind, und denen es mit einem Mal und zum voraus die Belehrung giebt, die sie sonst erst durch lange Erfahrung erhalten". 
Lo que no se menciona es la "soledad de la mente pensante en medio de un entorno incomprensivo y hostil", ${ }^{13}$ que Schopenhauer parece haber encontrado en la obra de Gracián como motivo de afinidad, y la concepción con la que Gracián idea la vida como campo de lucha existencial (desplegándose ya en el decimotercero de los trescientos aforismos del Oráculo manual). Así, pues, las exigencias de honorarios de Schopenhauer probablemente no fueron la única razón a la que se debe el hecho de que la traducción tardara hasta 1862, dos años después de su muerte, en publicarse y en convertirse -en numerosas y de continuo revisadas nuevas ediciones $-{ }^{14}$ en el medio de una fascinación alemana típica, cuyos prerrequisitos, sin embargo, sólo a finales del siglo XIX se convirtieron en parte del clima cultural. Así, Friedrich Nietzsche repetidamente hizo referencia a Gracián en los Fragmentos póstumos y asoció su pensamiento con el deseo de un compromiso existencial que él no veía satisfecho en la cultura de su propia época: "Gracián muestra en la experiencia vital una sabiduría e inteligencia con las que hoy no se puede comparar nada. Nosotros somos por cierto los observadores microscópicos de lo real; nuestras novelas saben ver (Balzac, Dickens), nadie, sin embargo, sabe exigir ni explicar”. ${ }^{15}$

Este énfasis en un "exigir" y "explicar" de manera racional, fundado en el pensamiento de Gracián, me impresiona como anticipación del atractivo de Werner Krauss -condenado a muerte-,

${ }^{13}$ Así Werner von Koppenfels, Graciáns (Über)Lebensjahre, Nachwort zu Balthasar Gracián: Handorakel und Kunst der Weltklugheit, p. 169.

${ }^{14}$ Cfr. Neumeister, "Prólogo", op. cit., pp. xxvirf.

${ }^{15}$ Friedrich Nietzsche: U II 3. Otoño de 1873-Invierno de 1873-1874 (30), p. 565. En el original alemán: "Gracian [sic] zeigt eine Weisheit und Klugjheit in der Lebenserfahrung, damit sich jetzt nichts vergleichen lässt. Wir snd wohl die Mikroskopiker des Wirklichen, unsere Romane verstehen zu sehen (Balzac, Dickens), nur zu fordern und zu erklären versteht niemand". Friedrich Nietzsche: Nachgelassene Fragmente (Herbst 1773 - Winter 1873-74 (30). En: Sämtliche Werke. Kritische Studienausgabe, Band vir. Hg. Von Giorgio Colli und Mazzino Montinari. München 1967-1977, p. 744. 
y quizá también fue decisivo para la lectura de intelectuales bajo la amenaza inminente del Nacional Socialismo. Walter Benjamin dedicó una copia de la traducción de Schopenhauer, publicada en 1931 por la editorial Insel, a su amigo Bertolt Brecht con un verso de la Ópera de los tres centavos, cuyo sarcasmo (aunque quizá algo irónicamente atenuado) es en el fondo incompatible con la autoconfianza de la visión marxista. Por otro lado, esta cita-de-Brecht en la dedicatoria-para-Brecht toca con exactitud lo que a lo mejor es el desafío más importante con el cual las reflexiones de Gracián confrontan el pensamiento: "Porque el hombre no es lo suficientemente astuto para esta vida" (Denn für dieses Leben ist der Mensch nicht schlau genug). ${ }^{16}$ Durante los años de su exilio entre 1933 y 1940, Brecht redactó glosas o comentarios a mano sobre veintiséis de los aforismos del Oráculo manual.

Aquel pulso, tan excéntrico como vivo, de las lecturas de Gracián en Alemania no se detuvo tras el final de la Segunda Guerra Mundial, aunque ahora tenía que obtener ventaja sobre una buena voluntad de autocrítica-nacional, pretendiendo recuperar, o al menos reforzar, la transparencia y calidez que el discurso de la Ilustración había ofrecido. Así, el historiador de la filosofía Hans Blumenberg, quien personalmente guardaba mucha distancia hacia sus colegas y lectores, en su libro de 1981 La legibilidad del mundo dedicó al Oráculo manual un capítulo admirable, que tiende a confundir la frialdad con la mirada imparcial del observador. Pero tal vez al final el hecho de que tales estudios, sin poder evitarlo, tomaron una posición alejada del bienintencionado consenso mayoritario, convirtió a la recepción alemana de Gracián en un campo minado en el cual cada movimiento suscita interpretaciones política e ideológicamente sobrecargadas. En todo caso es difícil imaginar que en tales condiciones sería posible un éxito inesperado y hasta sensacional, tal como el que Christopher

${ }^{16}$ Cfr. sobre este episodio de la historia de la recepción, Lethen: Im reißenden Strom der Translationen, op. cit., pp. 198 y ss. 
Maurer consiguió en los Estados Unidos con su traducción del Oráculo manual, publicada en 1992, a la cual al parecer la ola de la ingenua (quizá incluso refrescantemente ingenua) literatura de autoayuda llevó a una edición de más de cien mil ejemplares. ${ }^{17}$

Pero ¿quién fue ese autor del lejano siglo Xviı en España que hasta hoy tiene cautivados a lectores profesionales, así como a aquellos que buscan una orientación existencial? ¿Quién fue este autor, cuya voz distintiva ocasionalmente creemos oír en sus textos, por difícil que resulte extraer de los contornos de su pensamiento en nuestra imaginación los contornos de una figura individual? Tan pocos conocimientos concretos se tienen sobre la existencia individual de Baltasar Gracián que debemos ceñirnos a la especulación guiada por las líneas de convergencia entre sus textos y el horizonte del mundo histórico del que emergieron los mismos. ${ }^{18}$ Comenzó, concluyó y pasó la mayor parte de los cincuenta y siete ańos de su vida entre 1601 y 1658 en Aragón, aquel antiguo reino ibérico que, como vecino oriental de Castilla, estaba entonces, por un lado, bajo el dominio de un imperio mundial contrarreformista al principio de su fulminante declive, pero, por otro lado, había dado a este imperio mundial unos impulsos en esencia modernos al abrirse a Italia. Junto con su esposa Isabel de Castilla, el "Rey Católico" Fernando de Aragón había liderado a España a una temprana edad moderna y por lo tanto fue considerado por Maquiavelo como el único monarca vivo que correspondía a su imagen provocativamente racional de un gobernante político.

Dentro de Aragón y más allá de la frontera con Castilla, Gracián llevó una vida de constante movimiento espacial, como ya

\footnotetext{
${ }^{17}$ Neumeister, "Prólogo", op. cit., pp. xv s.

${ }^{18}$ También desde el punto de vista biográfico -y precisamente desde la perspectiva mencionada- el libro de Krauss, La doctrina de la vida, op. cit., es inigualable (Cfr. pp. 11-38).
} 
en esa época era típico para un jesuita. Realizó unos primeros años de formación bajo el cuidado de un tío clerical en Toledo, la antigua capital que dirigía su celosa y maligna mirada hacia el Madrid que paso a paso se iba consolidando como el nuevo centro. De regreso a Aragón, Gracián se incorporó a la Orden, se ordenó sacerdote y pasó el primer tramo de su tardía trayectoria como autor en la pequeńa ciudad de Huesca, siendo amigo del humanista noble Vicencio Juan de Lastanosa, bajo cuyo nombre se presentó a los primeros lectores el Oráculo manual. Ascendido al rango de confesor de poderosos aristócratas y famoso predicador en la proximidad madrileña a la Corte, consiguió méritos retóricos durante la victoria de las tropas castellanas sobre insurgentes catalanes en el año 1646. Mientras tanto, sus superiores le reprochaban por amenazar, a los creyentes de la parroquia que le había sido confiada en Valencia, con leerles una carta del infierno. Sin embargo, la Orden empleaba a Gracián mayormente como autoridad en la enseñanza teológica, lo que explica su creciente maestría en la argumentación racional, ya que los jesuitas, desde mediados del siglo Xvi y por voluntad de su padre fundador Ignacio de Loyola, subordinaron los medios del espíritu de la primera época moderna a los objetivos políticos de la Iglesia católica, lo que en especial se dio en el rechazo del protestantismo. No había por lo tanto ninguna contradicción institucional o intelectual entre el magisterio jesuita de Gracián y su desarrollo de las reflexiones sobre las formas contemporáneas de la conducta individual en la vida, la política y el discurso público en obras bajo los títulos de $E l$ Héroe (1637), El Político (1640), Agudeza y arte de ingenio (1641, 1648), El Discreto (1646), Oráculo manual (1647) y El Criticón (1651-1657). Más bien podemos suponer que Gracián satisfizo las expectativas de los superiores sustituyendo su propio nombre por el de su hermano Lorenzo como autor de las obras seculares. 
Como libro de más perdurable éxito de Baltasar Gracián, el Oráculo manual también ocupó un lugar especial con respecto al género, porque -como ya se ha mencionado- se presentó a los lectores, con palabras poco precisas, como una "colección" de pensamientos de un autor que tuvo éxito en España y especialmente en Francia. En el contexto histórico-cultural, sin embargo, ni tales antologías de la doctrina de la vida ni los "aforismos" como su forma textual -es decir: series de reflexiones breves con un alto nivel de abstracción- fueron excepcionales. ${ }^{19}$ Esto se aplicó asimismo al título. Allí, además de la referencia a los libros anteriores atribuidos a Lorenzo Gracián, convergieron tres tendencias contemporáneas, mismas que a los lectores educados con seguridad les habrán hecho recordar tradiciones de la Antigüedad clásica: el formato literalmente manual; la reivindicación de la autoridad de la prudencia asociada connotativamente al término oráculo; y la descripción de la forma en la que tal sabiduría se articulaba, pero quizá también se pretendía utilizar: como arte. ${ }^{20}$

Mucho más difícil resulta identificar una estructura que podría estar al fondo de la secuencia de los trescientos aforismos de Gracián. ${ }^{21}$ Esto es porque, por un lado, ciertamente no era la intención del autor presentar sus pensamientos y argumentos como un sistema cerrado. Al mismo tiempo, sin embargo, algunos elementos formales destacan demasiado en su secuencia para perder por completo de vista la dimensión de una forma englobante. Entre las características estructurales se encuentran: la descripción, de resuelta diferenciación, de la propia presencia en el primer aforismo, y el énfasis teológico casi sorprendente en el último; la acumulación de citas realmente "sacadas" de otras obras ya publicadas bajo el mismo nombre de autor en los primeros

${ }^{19} \mathrm{Cfr}$., sobre el lugar genus-histórico del Oráculo manual, Blanco, "Prefacio", op. cit., pp. 30 y ss.

${ }^{20}$ Sobre la interpretación del título y sus antecedentes en la historia intelectual, vid., von Koppenfels, Graciáns (Über)Lebensjahre, op. cit., p. 171.

${ }^{21}$ Vid. Blanco, Prefacio, op. cit., pp. 47 ss. y 63 ss. 
cien párrafos; ${ }^{22}$ la aparición de pensamientos sintetizadores o de agudeza sentenciosa en lugares destacados en razón de su número (por ejemplo en los aforismos 100, 150, 251); y -quizá ya como una transición hacia una postura individual de pensamiento- la inclinación de Gracián a iluminar ciertos temas desde diferentes ángulos a lo largo de una corta secuencia de aforismos, exponiéndolos a preguntas cada vez nuevas, sólo para luego abandonarlos, dando la impresión de un giro abrupto, sin que jamás se pueda descartar que luego vuelva a regresar a las mismas preguntas así planteadas.

Por tanto, en el curso de la lectura, ocasionalmente puede surgir la impresión de ciertas contradicciones que Gracián podría no haber revisado (o notado). Por ejemplo, cuando en el aforismo 46 recomienda a los lectores que resistan los impulsos espontáneos de disgusto, y en la siguiente reflexión sugiere justo que no se dejen guiar por sentimientos espontáneos de simpatía. Sin embargo, considero que esa apariencia de una incoherencia se debe a expectativas de sistematicidad hacia el texto que no son apropiadas. Por un lado, la intransigencia de la racionalidad de Gracián se demuestra precisamente en su resistencia a los "principios" o consejos absolutos y, por tanto, sesgados -en su opinión, cada caso y situación especial requiere soluciones específicas-. En segundo, y crucial, lugar, una de las fascinantes posibilidades de lectura del Oráculo manual consiste tal cual en poder seguir como una cadena de acontecimientos los movimientos de un pensador ágil.

Tal agilidad representa entonces una parte de la dificultad bien sorprendente (sobre todo para una "antología" en forma de aforismos), es más: la de la resistencia ${ }^{23}$ del texto frente a sus lectores. Porque los mismos lectores, de un aforismo al siguiente, y a menudo incluso dentro de un solo hilo de pensamiento, se ven

${ }^{22}$ Ibidem, p. 40.
${ }^{23}$ Cfr. Ibidem, pp. 72 y s.

236 / Hans Ulrich Gumbrecht 
obligados a revisar e intercambiar sus premisas. Más claramente que otras colecciones de aforismos (como las de La Rochefoucauld), las reflexiones de Gracián se desarrollan como pluralia tantum, en secuencias de pensamiento cada vez nuevas, cuyos enfoques individuales rara vez pueden citarse de forma aislada. No es infrecuente que tales secuencias aumenten la complejidad de las perspectivas sobre un tema específico hasta un grado apenas comprensible para el lector, sin sugerir nunca la existencia de un sistema de pensamiento coherente. También por esta razón, los aforismos de Gracián son una lectura persistentemente difícil.

Todos estos momentos estructurales no-estructurados no sólo complican la lectura en la actualidad, sino que también hacen imposible resumir el contenido del Oráculo manual con mayor concreción que la de su título, justo porque este contenido consiste en una multitud de movimientos, a menudo centrífugos, del pensamiento. El que quiera hacer un resumen, debe poner ciertos aforismos en el orden de un posible argumento en una manera que el propio texto no proporciona. $\mathrm{Al}$ menos, el mismo texto se introduce con aquel diagnóstico extrañamente ambivalente de su propia época: "Todo está ya en su punto, y el ser persona en el mayor. Más se requiere hoy para un sabio que antiguamente para siete; $y$ más es menester para tratar con un solo hombre en estos tiempos que con todo un pueblo en los pasados".

$\mathrm{Si}$ podemos asumir que con el concepto de "ser persona" Gracián se refiere a la forma y la capacidad del autónomo actuar humano (en nuestra retrospectiva: característico de la temprana Modernidad), la primera frase del aforismo de apertura tiene un tono a todas luces optimista. Pero este optimismo de inmediato se contrasta con la experiencia de la complejidad mucho más elevada de la vida social cotidiana ("más es menester para tratar con un solo hombre en estos tiempos que con todo un pueblo en los pasados"). La capacidad de actuar "plenamente desarrollada" se enfrenta, pues, a un desafío del que en un principio no se puede presuponer con garantía que se logre cumplir. 
Varias reflexiones del Oráculo manual convierten esa primera observación de la complejidad en una acusación de la decadencia moral de sus propios tiempos. Así, en el aforismo 280: "Hombre de ley. Está acabado el buen proceder, andan desmentidas las obligaciones, ai pocas correspondencias buenas: al mejor servicio, el peor galardón, a uso ya de todo el mundo. Ai naciones enteras proclibes al maltrato: de unas se teme siempre la traición; de otras, la inconstancia; y de otras, el engaño".

Son la voluntad y la necesidad de sobrevivir en un tal ambiente de instituciones colapsadas (no sobrevivir manteniendo altos estándares morales, sino simplemente evitar el estatus de víctima) las que convierten la vida cotidiana en una continua "milicia contra la malicia del hombre". Y esta milicia tiene lugar en un nivel de sutileza estratégica apenas manejable, como el aforismo 13 trae a la mente -en apariencia inspirado por la imagen de la pelea entre esgrimidores, la cual fascinaba a muchos autores del mundo de Gracián-:

Obrar de intención, ya segunda, y ya primera. Milicia es la vida del hombre contra la malicia del hombre, pelea la sagazidad con estratagemas de intención. Nunca obra lo que indica, apunta, sí, para deslumbrar; amaga al aire con destreza y executa en la impensada realidad, atenta siempre a desmentir. Echa una intención para assegurarse de la émula atención, y rebuelve luego contra ella venciendo por lo impensado. Pero la penetrante inteligencia la previene con atenciones, la azecha con reflexas, entiende siempre lo contrario de lo que quiere que entienda, y conoce luego qualquier intentar de falso; dexa passar toda primera intención, y está en espera a la segunda y aun a la tercera [...].

No es el vicio de los enemigos potenciales y no es su condena lo que aquí ocupa un puesto destacado en las reflexiones del Oráculo manual, sino la inteligencia estratégica, a menudo desafiante y amenazante, de los oponentes.

Tal sobrecarga permanente en la vida cotidiana de un imperio en proceso de hundimiento debe haber sido, me parece, a raíz de 
la decisión de Gracián de concentrarse exclusivamente en casos y modos de la vida secular, la misma decisión que se recalca hacia el final del libro (aforismo 251) como la "regla de gran maestro": "Hanse de procurar los medios humanos como si no huviesse divinos, y los divinos como si no huviesse humanos. Regla de gran maestro; no ai que ańadir comento". Estas palabras recuerdan una fórmula que apareció repetidas ocasiones en los textos de teólogos y filósofos contemporáneos ante la confrontación con problemas de particular complejidad: "etsi Deus non esset" ("y si Dios no se diera”). Existe una obligación práctica, así se asume, de prescindir de la ayuda de los "medios divinos", precisamente porque la confianza en ellos podría llevar a negligencia y debilidad en la lucha de la vida cotidiana. Tanto en el plano teológico como en el de la reflexión sobre una vida cotidiana secular, la fórmula se malinterpretaría como síntoma de un ateísmo temprano que tratase de esconderse detrás de la forma gramatical de un irrealis ("esset"). De manera particular en lo que respecta a Gracián, tenemos todo tipo de razones para suponer que para él la existencia de Dios era incuestionable. Cuando sugirió entonces una concentración en la aplicación exclusiva de los "bienes humanos como si no hubiese divinos", él se guio por una necesidad pragmática. Sólo una concentración exclusiva en el mundo secular y sus estrategias parecía mantener abierta la posibilidad de la supervivencia individual.

La "persona”, perfilándose ya en el primer aforismo y recurriendo regularmente, es el concepto normativo central del Oráculo manual, en el cual convergen las competencias estratégicas más importantes de la supervivencia individual. ${ }^{24}$ Como persona uno emerge, en primer lugar, más de las confrontaciones con

\footnotetext{
${ }^{24}$ En este sentido, "persona” puede efectivamente considerarse un sinónimo del concepto tipológico de "subjetividad de la temprana Modernidad" que es común en la historia de la filosofía. Aunque incluye la capacidad de ocultar los propios impulsos o intenciones, ciertamente no debe equipararse con el significado de "persona" como "máscara", lo cual es perfectamente concebible en otros contextos.
} 
problemas prácticos que de las lecturas o instrucciones abstractas: "Un empeño en su ocasión hizo personas a muchos, assí como un ahogo saca nadadores. Desta suerte descubrieron muchos el valor, y aun el saber, que quedara sepultado en su encogimiento si no se huviera ofrecido la ocasión" (aforismo 265). En segundo lugar, empero, las situaciones problemáticas sólo contribuyen al convertirse en persona si se experimentan abiertamente, es decir, con la mayor sensibilidad: "No ser malo de puro bueno. Eslo el que nunca se enoja: tienen poco de personas los insensibles. No nace siempre de indolencia, sino de incapacidad. Un sentimiento en su ocasión es acto personal" (266). En la conversación con los demás -en tercer lugar- la persona muestra y demuestra su valía, porque aquí surte efecto la máxima flexibilidad estratégica en la reacción ante los demás:

Tener el arte de conversar, en que se haze muestra de ser persona. En ningún exercicio humano se requiere más la atención, por ser el más ordinario del vivir. Aquí es el perderse o el ganarse; que, si es necessaria la advertencia para escrivir una carta, con ser conversación de pensado, y por escrito, ¡quánto más en la ordinaria, donde se haze examen pronto de la discreción! Toman los peritos el pulso al ánimo en la lengua, y en fe de ella dixo el Sabio: "Habla, si quieres que te conozca". Tienen algunos por arte en la conversación el ir sin ella, que ha de ser olgada, como el vestir, entiéndese entre mui amigos; que quando es de respeto ha de ser más substancial, y que indique la mucha substancia de la persona. Para acertarse se ha de ajustar al genio y al ingenio de los que tercian. No ha de afetar el ser censor de las palabras, que será tenido por gramático, ni menos fiscal de las razones, que le hurtarán todos el trato y le vedarán la comunicación. La discreción en el hablar importa más que la eloqüencia (aforismo 148).

Después de todo, según Gracián, nadie nace ya con el estatus de persona, y el camino hacia ese estatus pasa por una constante labor de autoperfeccionamiento, guiado por la autobservación 
crítica: "Conocer la pię̧a que le falta. Fueran muchos mui personas si no les faltara un algo, sin el qual nunca llegan al colmo del perfecto ser. [...] Todos estos desaires, si se advirtiessen, se podrían suplir con facilidad, que el cuidado puede hazer de la costumbre segunda naturaleza" (aforismo 238).

En comparación con la diferenciación y la sutileza del comportamiento -los cuales deben caracterizar a la persona-, la forma de la sociedad como el escenario en el cual éstos se deben probar parece sorprendentemente elemental. Gracián presupone como hecho dado e inalterable la existencia de una clase de "superiores" -nobles y subalternos- con los que en la mejor manera estratégica hay que llegar a acuerdos, porque su poder superior por jerarquía -con independencia de su dignidad moral o sus logros- no puede ser objeto de desplazamientos o aun de transformaciones. De manera análoga, existe una burda clase baja ("vulgo", "comunes") sin vocación de ascenso, de la que la persona debe marcar distancia y cuyas interacciones debe evitar -entre otras razones porque al parecer allí la estupidez está en su casa-. Similarmente arcaica parece la asimetría entre los sexos, asumida de fijo, pero sólo una vez hecha explícita: "Lo mejor de un hombre es parecerlo; que la muger puede afectar con perfección lo varonil, y no al contrario" (275). Y aún muy en el sentido del concepto tardío medieval de "fortuna", esta misma aparece como un poder que, independientemente de los méritos individuales, favorece a algunos y perjudica a otros: "Tener tanteada su fortuna: para el proceder, para el empeñarse [...]. El que la observó favorable prosiga con despejo, que suele apasionarse por los osados; y aun, como vizarra, por los jóvenes. No obre el que es infeliz, retírese, ni le dé lugar de dos infelicidades [...]" (aforismo 36).

En este escenario relativamente sencillo de la vida como lucha constante, lucha tan compleja como dramática, se deben aplicar sobre todo dos reglas básicas de conducta a las que Gracián se adhiere por principio, a pesar de todo su insistir en el ser abierto hacia situaciones en su respectiva singularidad. Ya el tercer afo- 
rismo recomienda justo no jugar con cartas abiertas. Hay que "cubrir" las intenciones y pasiones, pero al mismo tiempo hay que ser capaz de "descifrar" (palabra que a lo largo del texto se eleva a expresión favorita de Gracián) en la medida de lo posible la existencia oculta de otras personas. De igual importancia es comprender la necesidad de obligar a otras personas, especialmente a las de mayor nivel social, a través de favores que se convierten en compromisos, en lugar de avergonzarlos o incluso derrotarlos: "Atención a obligar. Los más no hablan ni obran como quien son, sino como les obligan [...]" (aforismo 226).

En su concentración secular, su estricta racionalidad y su consistente dejar fuera de los "medios divinos" así como de los valores morales, estos elementos centrales de la enseñanza de Gracián evocan una específica impresión de frialdad y de obligatoriedad distante, sin que en sus contenidos y valores parezcan sorprendentes o hasta excéntricos. En cambio, muchas de las reflexiones que conducen a estos resultados relativamente convencionales alcanzan un grado de complejidad que puede agobiar al lector.

De este modo, el Oráculo manual quizá nunca se habría elevado por encima de los muchos otros tratados de prudencia en su propia época si no hubiera sido escrito en el estilo de lo que entonces se llamaba "conceptismo". Es uno de los lugares comunes (de inmediato convincentes) de la literatura secundaria afirmar que los objetos y argumentos del pensamiento de Gracián no se dejan separar de este gesto estilístico. Pero en lo que respecta a la descripción histórica del conceptismo, nos encontramos con mucho menos claridad y consenso. Los usuales artículos en los manuales de consulta muestran un grado insólito de divergencia y son de poca utilidad, probablemente también por contentarse demasiado con delimitar el conceptismo contra el "culteranismo" -un contra-concepto estilístico asimismo escurridizo de la misma 
época-. De todas maneras, en lo concerniente al culteranismo, se puede remarcar-dicho de manera bien impresionista-, un excedente de las palabras en relación con los contenidos que los mismos articulan, ante lo cual hay que destacar el contraste que luego marca la escasez lingüística del conceptismo. Cabe señalar también que la referencia del conceptismo a la palabra "concepto" no alude tanto a su significado en el sentido de "término", sino más bien a una variante que se acerca a la palabra inglesa conceit, es decir, a la "imaginación" o "construcción de pensamientos". Se trata, pues, de configuraciones conceptuales que se establecen como diferentes piezas de un conjunto.

El tratado extenso de Gracián sobre el conceptismo, titulado Agudeza y arte de ingenio, continúa -como en tantas otras ocasiones- la reflexión en direcciones distintas sin llegar a un término práctico, quizá porque él presuntamente estaba en primer lugar interesado en ilustrar el fenómeno en la máxima diferenciación. Al menos el libro contribuye a la explicación de la "agudeza" estilística-intelectual del conceptismo como medio y "arte de ingenio", desde una perspectiva que al principio es sorprendente. En vez de vincular la "agudeza" con cualidades formales, como cabe esperar a primera vista, el tratado la asocia una y otra vez con el lado de la "sustancia", que en la filosofía aristotélica forma el signo junto con la "forma". Ya en el prefacio "Al lector" se habla de "tropos y figuras retóricas" como "fundamentos materiales" 25 del espíritu; luego de la agudeza como "pasto del alma" ${ }^{26}$ y por último -con una claridad particularmente bella- como "luz" de la mente: "Entendimiento sin agudeza ni concepto es sol sin luz, sin rayos, y cuantos brillan en las celestes lumbreras son materiales con los del ingenio". ${ }^{27}$

\footnotetext{
${ }^{25}$ Citado según la edición de Santos Alonso, en Baltasar Gracián, Obras completas, aquí, p. 436.

${ }^{26}$ Ibidem, p. 438.

${ }^{27}$ Ibidem, p. 439.
} 
A lo largo de los ochenta y tres discursos de Agudeza y arte de ingenio se acumulan más indicios sugiriendo que Gracián asignó al estilo de su lenguaje principalmente la dimensión de la sustancia. El estilo se deja "percibir, no definir", ${ }^{28}$ según dice un pasaje. Sobre todo, enfatiza repetidas veces que el estilo resulta de la relación entre diferentes elementos perceptibles: "la proporción entre las partes de lo visible es la hermosura, entre los sonidos la consonancia”. ${ }^{29} \mathrm{Al}$ final, en un intento de describir el estilo ideal, las palabras se atribuyen al lado de lo material y los pensamientos al lado de la forma: "Dos cosas hacen perfecto un estilo, lo material de las palabras y lo formal de los pensamientos". ${ }^{30}$

También en lo que respecta al estilo propio de Gracián, a su "luminosidad", a sus "incomparables dotes" en cuanto a la forma ${ }^{31} \mathrm{y}$ a los "fuegos artificiales" ${ }^{32}$ de su prosa, Werner Krauss ha llegado mucho más allá de las conclusiones de otros especialistas en Letras. Sobre todo, su análisis confirma la intuición de que el término "concepto" trae a la vista menos una conceptualidad, "sino que intenta en primer línea señalar las relaciones entre las cosas" - y que se trata de una relación entre las "cosas" a las cuales hacen referencia las palabras, no sólo una relación entre las palabras- ${ }^{33}$ Esta conclusión le permite a Krauss comprender cómo es que para Gracián el pensamiento sólo "vive en el idioma. Gracián quiere dar vida a las relaciones conceptuales". El lector, sin embargo, no es capaz de sin más -o incluso completamente- seguir este movimiento. Más bien, su pensamiento es activado por ello, de modo que él puede "ayudar" al autor "como interlocutor contrario" o hasta terminar por su propia ejecución la reflexión

28 "Es este ser uno de aquellos que son más conocidos a bulto, y menos a precisión; déjase percibir, no definir". Ibidem, p. 440.

${ }^{29}$ Ibidem, p. 441.

${ }^{30}$ Ibidem, p. 788.

${ }^{31}$ Krauss, La doctrina de la vida, op. cit., p. 28.

${ }^{32}$ Ibidem, p. 230.

${ }^{33}$ Ibidem, p. 222.

244 / Hans Ulrich Gumbrecht 
del mismo autor: "El estilo de Gracián impulsa a la reflexión y el retórico a la huída. El autor siempre va delante del lector. El sentido no se revela hasta que se relaciona todo, se especifican las afirmaciones, se comparan los conceptos con sus contrarios y se traducen las contradicciones según el sistema de Gracián”. ${ }^{34}$

El desafío de la prosa de Gracián y de las reacciones que suscita difícilmente se deja captar con mayor precisión. Y así la descripción de Krauss nos anima a atrevernos a dar el paso hacia una inferencia filosófica que ella posibilita sin llevarla a cabo. Cuando Gracián concibe la forma y la "agudeza" de su lenguaje como una sustancia material que debe ser percibida mediante los sentidos, es en particular al cuerpo humano al que acerca el estilo. Pero es precisamente alrededor del cuerpo donde se despliega la dimensión del espacio. Por ello resulta evidente experimentar la relación y el movimiento entre los pensamientos de Gracián como acontecimiento espacial; y esto en un sentido literal, no-metafórico.

Porque en apariencia el propio Gracián entendía las estructuras surgidas de sus palabras y pensamientos como configuraciones en el espacio, análogas a las relaciones de las cosas y los cuerpos en el espacio (justo en este sentido es significativo que él -al igual que Krauss- casi nunca mantiene una distinción estricta entre los pensamientos y las cosas). Se podría decir que los pensamientos forman un conjunto, como los cuerpos celestes dentro de una constelación. Y porque éste es el caso, también el pensamiento y la lectura se convierten en una realización en el espacio, que depende de la presencia de los cuerpos. ${ }^{35}$

Esta hipótesis sugiere, en varios planos, una lectura más concreta, precisamente no metafórica, de muchos de los aforismos del Oráculo manual. Por ejemplo, deberíamos atrevernos a asumir

\footnotetext{
${ }^{34}$ Ibidem, p. 225.

${ }^{35}$ El primer impulso para esta consideración lo debo a una conversación en Friedrichshafen (sobre Gracián, por supuesto) con Gill Zimmermann. Friedemann Kreuder me permitió luego continuarlo en su conferencia en Maguncia sobre el teatro de la época moderna.
} 
la premisa de que Gracián va en serio cuando escribe sobre la "profundidad" del cuerpo como espacio de pensamientos: "Pecho sin secreto es carta avierta. Donde ai fondo están los secretos profundos, que ai grandes espacios y ensenadas donde se hunden las cosas de monta" (aforismo 179). De manera muy similar, pero ahora en dirección horizontal, visualiza la sabiduría como un movimiento físico a tientas hacia adelante en el espacio:

Arte en el intentar. La necedad siempre entra de rondón, que todos los necios son audazes. Su misma simplicidad, que les impide primero la advertencia para los reparos, les quita después el sentimiento para los desaires. Pero la cordura entra con grande tiento. Son sus batidores la advertencia y el recato, ellos van descubriendo para proceder sin peligro. Todo arrojamiento está condenado por la Discreción a despeño, aunque tal vez lo absuelva la ventura. Conviene ir detenido donde se teme mucho fondo: vaya intentando la sagacidad y ganando tierra la prudencia. Ai grandes vaxíos hoi en el trato humano: conviene ir siempre calando sonda (aforismo 78).

Pero si los pensamientos se perciben físicamente, también pueden provocar sensaciones físicas, como la de saciedad o de hambre:

Estómago para grandes vocados de la fortuna. En el cuerpo de la prudencia no es la parte menos importante un gran buche, que de grandes partes se compone una gran capacidad. No se embaraça con las buenas dichas quien merece otras mayores; lo que es ahíto en unos es hambre en otros. Ai muchos que se les gasta qualquier mui importante manjar por la cortedad de su natural, no acostumbrado ni nacido para tan sublimes empleos; açedáseles el trato, y con los humos que se levantan de la postiza honra viene a desvanecérseles la cabeça. Corren gran peligro en los lugares altos, y no caben en sí porque no cabe en ellos la suerte. Muestre, pues, el varón grande que aun le quedan ensanches para cosas mayores, y huiga con especial cuidado de todo lo que puede dar indicio de angosto coraçón (aforismo 102). 
Tal severidad de lo literal llega hasta plantear la posibilidad de lesiones corporales: "Saber tomar las cosas. Nunca al repelo, aunque vengan. Todas tienen haz y envés. La mejor y más favorable, si se toma por el corte, lastima" (aforismo 224). Consecuentemente, al final también la sensualidad de las palabras se presenta como un cumplimiento del cuerpo: "Siempre se ha de llevar la voca llena de açúcar para confitar palabras, que saben bien a los mismos enemigos" (aforismo 267).

Es verdad que lo que estoy intentando visualizar como la espacialización del pensamiento y como espacio del pensar no es algo que el propio Baltasar Gracián percibió como una posibilidad de combinar la reflexión y la prosa que él haya sido el primero en proporcinar. Más bien parece simplemente haberla presupuesto, como una dimensión elemental de su entorno cultural que él utilizaba con particular consistencia. De hecho, para el contexto más amplio del Siglo de Oro en España ${ }^{36}$ se puede hablar de una prioridad general, o mejor: de una posición en el primer plano, de la dimensión espacial, que había resultado de una configuración históricamente particular en el umbral entre la Edad Media y la temprana Modernidad. De manera contraria a la impresión, sobre todo en España hasta el día de hoy, de un "retraso" de la historia cultural nacional en comparación con las sociedades centroeuropeas, una multitud de síntomas muestran que -quizá debido a la singular coexistencia de las tres religiones monoteístas durante los siglos precedentes- la mentalidad de la temprana Modernidad estaba particularmente desarrollada en la Península Ibérica alrededor del año 1500. Desarrollada como una autocomprensión ("cartesiana" desde el punto de vista tipológico) del hombre como

${ }^{36}$ Cfr. en este contexto -aunque todavía sin la tesis de la prioridad del espaciomi libro Eine Geschichte der spanischen Literatur, especialmente los capítulos sobre los ańos 1474-1556 (pp. 175-293) y 1556-1700 (pp. 294-473).

El espacio del pensar de Baltasar Gracián / 247 
una conciencia que se enfrentaba al mundo de las cosas en forma de un observador (en lugar de habitar el mundo con el cuerpo como creación de Dios) y que pronto comenzó a disponer de este mundo de una manera que lo cambia. Fue la misma actitud que, a los ojos de Maquiavelo, había hecho de Fernando de Aragón el ideal del nuevo gobernante.

Sin embargo, como el imperio mundial español pronto hizo del rechazo y la contención de las confesiones reformistas su misión -como una práctica religiosa que toma la perspectiva del sujeto, por así decirlo- una visión tradicional del mundo se colocó por encima de esa mentalidad móvil de la Modernidad, volviendo a asignar a las personas, en cuerpo y alma, a sus lugares fijos en un mundo concebido como espacio. La duplicidad de los héroes centrales en el género de la novela picaresca que surgió después de 1550 ilustra justo esta situación. Lazarillo de Tormes es el primero entre estos héroes en lograr, como sujeto, un ascenso limitado dentro de esa sociedad contemporánea que lo había confinado, como creación divina, a su nivel más bajo.

Cuanto más España quedaba atrás en el plano militar y económico desde finales del siglo XVI, más drásticas resultaron la escenificación y la implementación de la cultura premoderna en la región. Esto incluía la elección de Madrid como nueva capital siendo el supuesto punto medio geográfico del imperio; la construcción del Escorial como monasterio y palacio en las montañas por el lado oriental sobre la capital; el ritual estricto de la Corte que con múltiples gestos hacía visible la distancia del monarca y su familia hacia los súbditos; y sobre todo el ascenso del teatro que llegó a ser la forma más popular de entretenimiento, pero también de reflexión, en Madrid.

Muy al contrario del dominio -calando cada vez más en el proceso europeo de la Modernidad- de la conciencia que quería ver 
más allá de todo lo material y devaluarlo como mera "apariencia", en el mundo clásico español de la sustancia y del espacio ni siquiera se podía concebir una modalidad del ser sin materialidad. Es ésta una condición previa de la doctrina de la vida de Gracián que difícilmente puede ser sobreestimada en sus consecuencias, descuidada por no pocos intérpretes, porque -en el sentido de una perspectiva que ha sido común desde la Ilustración y hasta la actualidad-malinterpretan el Oráculo manual como un enjuiciamiento de la "apariencia" frente al "ser": "Hazer, y hazer parecer. Las cosas no passan por lo que son, sino por lo que parecen. Valer y saberlo mostrar es valer dos vezes. Lo que no se ve es como si no fuesse. No tiene su veneración la razón misma donde no tiene cara de tal. [...] La buena exterioridad es la mejor recomendación de la perfección interior" (aforismo 130).

En lugar de ser desenmascarado por el ser, así se lee (¡en el indicativo!), las apariencias doblan al ser. Radicalizando este pensamiento, el aforismo 231 afirma que un objeto es "nada" antes de que su forma no haya alcanzado su remate total como apariencia:

Gozar de un golpe el objecto grande, aunque embaraça el juizio de las partes, de por sí adequa el gusto. Antes de ser todo es nada, y en el començar a ser se está aun mui dentro de su nada. El ver guisar el manjar más regalado sirve antes de asco que de apetito. Recátese, pues, todo gran maestro de que le vean sus obras en embrión. Aprenda de la naturaleza a no exponerlas hasta que puedan parecer. ${ }^{37}$

Es como "alteza de ánimo" que Gracián describe un impulso que violentamente expande los pensamientos hacia su apariencia: "Dondequiera que se halla, se descuella, y aun tal vez, desmentida

${ }^{37}$ En el prefacio de su drama "El Gran Teatro del Mundo", Pedro de Calderón de la Barca pone en escena el acontecimiento de la creación del mundo como una transición de la nada como sustancia no formada a la apariencia como sustancia formada. 
de la invidia de la suerte, rebienta por campear" (aforismo 128). "El ostentar" se considera, por tanto, una condición necesaria, nada devaluable moralmente, de la grandeza humana, y nuestra tesis sobre el origen histórico de esta premisa es reforzada por el hecho de que Gracián la consideraba desarrollada de modo particular en la España de su tiempo:

Es el lucimiento de las prendas. Ai vez para cada una: lógrese, que no será cada día el de su triunfo. Ai sugetos vizarros en quienes lo poco luze mucho, y lo mucho hasta admirar. Quando la ostentativa se junta con la eminencia, passa por prodigio. Ai naciones ostentosas, y la Espańola lo es con superioridad. Fue la luz pronto lucimiento de todo lo criado. Llena mucho el ostentar, suple mucho y da un segundo ser a todo, y más quando la realidad se afiança (aforismo 277).

En última instancia, al mundo como lugar de la existencia humana también le pertenece un lugar cosmológico concreto en la creación: "En el Cielo todo es contento, en el Infierno todo es pesar. En el mundo, como en medio, uno y otro. Estamos entre dos extremos, y assí se participa de entrambos" (aforismo 211). Es justamente este espacio de existencia por el que se extienden las posibilidades de nuestro comportamiento y nuestros acciones: "En las grandes capacidades siempre ai grandes distancias hasta los últimos trances: ai mucho que andar de un extremo a otro" (aforismo 47). Incluso el uso de la razón se articula en el espacio porque Gracián lo piensa en relación con el cuerpo: "El que se calçó al principio el entendimiento al revés, en todo lo demás prosigue desse modo: lleva entre pies lo que avía de poner sobre su cabeza; haze siniestra de la diestra y assí es tan zurdo en todo su proceder" (aforismo 268).

Pensar en el espacio también explica la especificidad del lenguaje y del estilo de Gracián. Si en ellos se juntan repetidamente términos y cosas como constelaciones, entonces los sustantivos y los pronombres que los sustituyen deben dominar en una densi- 
dad inusual que a menudo abruma la comprensión. Los verbos pasan a un segundo plano: "El pensamiento no precisa de la dinámica verbal, porque lo único que se intenta es hacerlo reflejar en el espejo del idioma". ${ }^{38}$ Algunas veces los verbos aparecen en la forma gramatical del infinitivo, donde una progresión (“va”), reclamada de ellos como "palabras de tiempo", se congela en estática (“ir"). No pocas veces, la posición sintáctica de los verbos esperados nada más permanece vacía, lo que resulta en que muchas de las frases de Gracián son gramaticalmente incompletas y, desde el punto de vista estilístico, elípticas - pero sobre todo aumenta aún más el efecto de la condensación-. Pero también los pares de palabras como "ni/ni", "tanto/como" y "cuanto/ tanto" forman parte del repertorio de dispositivos que permiten la espacialización en la imaginación del lector, porque sugieren simetrías, asimetrías o interacciones entre los significados y sus fenómenos de referencia. Al final, todas estas formas convergen en las impresiones contradictorias de la sobrecarga intelectual y la concreción existencialmente fascinante. Penetran en la prosa del Oráculo manual-y eclipsan el rigor meramente racional de su argumentación en estilo de la temprana Modernidad-.

También para Werner Krauss la fascinación del pensamiento de Gracián resultó sobre todo de esta concreción. Sin embargo, a pesar de toda su admiración, Krauss no olvidó que el gesto basado en sustancia y forma no había desarrollado históricamente -en contraste con el moderno movimiento reflexivo centrado en la conciencia- un futuro más allá del siglo XVII. Por esta razón, lo distanció de la filosofía como discurso y práctica de la abstracción -a lo mejor de manera implícita haciendo referencia al detalle de que fue justo gracias a este contraste con la Modernidad, y por

${ }^{38}$ Krauss, La doctrina de la vida, op. cit., p. 231.

El espacio del pensar de Baltasar Gracián / 25 I 
lo tanto gracias a la ausencia de la filosofía, que había surgido la fuerza particular de la cultura clásica en España-: "La conciencia de este estilo conceptista no busca los conceptos abstractos. Los conceptos aparecen como presos, arrebatados por el movimiento del lenguaje. La prosa conceptista fué el precedente de una filosofía que en España no llegó a consolidarse". ${ }^{39}$

Así que realmente podría haber sido el espacio de pensar frío -y premoderno- de Baltasar Gracián, nacido de la vida en el caos del ocaso, lo que le dio a Krauss un punto de apoyo para sobrevivir durante los meses del corredor de la muerte. El movimiento intelectual dentro de este espacio no sólo mantuvo su mente despierta y activa, sino que, debido a su índole espacial, por fuerza también debía ocupar su cuerpo, cuya aniquilación era un hecho consumado.

Por supuesto, no tomaríamos suficientemente en serio la situación extrema en la que se escribió el libro sobre Gracián de Werner Krauss, si de las huellas de su lectura sacáramos conclusiones precipitadas sobre potenciales de experiencia que el Oráculo manual podría ofrecernos más de tres cuartos de siglo más tarde. Después de todo, de modo particular en Alemania, el periodo que siguió a la destrucción del nacionalsocialismo estuvo lleno de etapas de recuperación (al principio a través de dos caminos de formas e ideologías políticas rivales) en el proceso de la Modernidad y eso significa: lleno de una distancia cada vez mayor hacia el mundo del pensar espacializado de Gracián. Esas etapas han fortalecido -ciertamente para el beneficio político general- el dominio de la conciencia y la racionalidad, hasta que se acoplaron cada vez más a la matriz de la tecnología electrónica durante las últimas tres décadas.

En la mayoría de las profesiones, y más aún en los crecientes espacios de tiempo libre de la actualidad, por lo tanto, el sujeto moderno ya no se enfrenta como observador a un mundo de co-

${ }^{39}$ Ibidem, p. 233 (cursivas en el original).

252 / Hans Ulrich Gumbrecht 
sas percibidas, sino que entra en una fusión cada vez más estrecha con los exuberantes flujos de la información y del software como su matriz. La impresión, al inicio percibida como liberadora en los ańos setenta y ochenta, de que el mundo resulta de una multiplicidad de "construcciones sociales", se ha convertido, por lo tanto, en la dificultad permanente para distinguir entre la información y los hechos, entre fake news y news, dificultad a la que reaccionamos con un anhelo de la experiencia inmediata de las cosas y del carácter vinculante de los valores u orientaciones.

Este punto sin salida de una existencia que se basa en exclusiva en la conciencia, sin embargo, es sólo una de las dos dimensiones de una disforia que hoy día aparentemente se está extendiendo a nivel mundial. Confluye con ella la sensación de una permanente sobrecarga individual derivada de la complejidad cotidiana, que pertenece a la vida en un nuevo modo temporal que puede describirse como "amplio presente". ${ }^{40}$ Desde la transición del siglo XVIII al XIX, el modo temporal de la así llamada "visión del mundo histórica” había establecido en las culturas occidentales la convicción de que en la acción a niveles colectivo e individual se estaba efectuando el diseño de un futuro abierto (con mayor precisión: el diseño de un futuro abierto desde un presente de transición constante y sobre la base de orientaciones de un pasado que se está quedando atrás de nosotros). El futuro, en cambio, hoy parece estar ocupado por peligros que se mueven irreversiblemente hacia nosotros. Dado que, al mismo tiempo, el pasado ya no queda atrás de nosotros (las capacidades de almacenamiento electrónico, en particular, no permiten olvidar, ni siquiera olvidar el modo temporal anterior de la "conciencia histórica"), todos los fenómenos, pensamientos y posibilidades están reunidos en el presente único, ahora ampliándose cada vez más, que ya no es un presente de transición, sino un presente que nos agobia en su complejidad.

\footnotetext{
${ }^{40}$ Sobre ello (con todo detalle) mis libros Breite Gegenwart, y Después de 1945. La latencia como origen del presente.
} 
En el punto en que la fusión entre la conciencia y el software se intersecta con nuestro "amplio presente", el anhelo de experiencias sensoriales inmediatas y de valores vinculantes se transforma en la elemental necesidad existencial -que ya casi no se puede concebir en términos de contenidos- de poder agarrarse a algo. Y esta necesidad está siendo satisfecha en el estilo político desde hace algunos años por dos tendencias que, según su autocomprensión, son opuestas, pero que forman equivalentes funcionales en un aspecto decisivo, a saber: que con gestos y conceptos aparentemente elementales sugieren una (irresponsable) claridad que queda por debajo de la complejidad que vivimos. Me gustaría caracterizar una de estas dos variantes como "política de la resonancia”, porque no se basa en la aprobación y la solidaridad que surge de la misma, sino más bien en una resonancia creada por la impresión de una supuesta autenticidad. Todos conocemos a maestros de esta política de la resonancia con su talento -encubriendo posturas y estrategias incoherentes- para asociar a potenciales seguidores con una impresión de franqueza sin disfraz.

Al lado opuesto del espectro político-público, la "corrección política" queda por debajo de la complejidad de nuestro presente con su afirmación de que las normas y conceptos estratégicos del pasado, tal como se habían derivado sobre todo de la "visión histórica del mundo", siguen siendo suficientes hoy día para resolver los problemas a corto y largo plazo. El contraste entre lo políticamente correcto y lo políticamente resonante puede explicar por qué a la fecha un número cada vez mayor de sociedades creen que están pasando por un proceso de división irreconciliable, yendo más allá de los antagonismos políticos del pasado. Se sobreentiende que los partidos y protagonistas del presente sin excepción reivindican (y deben reivindicar) ser la única alternativa a la -tan paralizante como arriesgada- tensión entre dos polos de complejidad disminuida. Es una cuestión por completo diferente si tal alternativa realmente forma parte del escenario político de hoy. 
Con respecto al Oráculo manual de Baltasar Gracián, no obstante, se plantea la cuestión, más bien existencial que política, de cómo podría ser concebida una posibilidad legítima $-\mathrm{y}$ quiero decir: políticamente no problemática, pero quizá también irrelevante- de satisfacer el anhelo individual de apoyo sin caer en las versiones comunes del quedar por debajo de la complejidad. Esta cuestión me ayudó a entender la fascinación con la que reaccioné al texto de Gracián durante los meses de su traducción -y con la que vi reaccionar a amigos que lo leyeron conmigo-. Sólo de modo muy incidental fue una fascinación a través de observaciones, argumentos racionales o recomendaciones del autor. Estos contenidos, o pertenecen al mundo del siglo xvir que es dramático en otro sentido ("la vida como milicia"), o pueden adaptarse al nivel de banalidad de la literatura de autoayuda tan popular hoy en día ("es mejor comprometer a los demás que derrotarlos"). Lo que en realidad me cautivó fue la concreción fría que había emergido en el espacio del pensar de Gracián, aquella concreción de singularidad y tridimensionalidad de los pensamientos y fenómenos -mientras que la imagen del autor seguía siendo una promesa fugaz de concreción-. Ciertamente, esta concreción sólo existía en las ideas que el texto suscitaba en mí; era una concreción que yo no podía llevar a mundos fuera del trabajo sobre el texto de Gracián, lo que quizá no fue tan diferente para Werner Krauss y el trabajo suyo sobre el Oráculo manual. 匽

Traducción de Dominik Hofmann

BiBLIOGRAFÍA

Blanco, Emilio. "Prefacio", en Baltasar Gracián, Oráculo manual y arte de prudencia, tr. de E. B., Madrid, Letras Hispánicas, 1993, pp. 17-87.

Cartwright, David D. Schopenhauer: A Biography, Cambridge, Cambridge University Press, 2010.

Chartier, Roger. L'Oeuvre, l'Atelier et la Scène. Trois études de mobilité textuelle, París, Classiq Garnier, 2014. 
Gracián, Baltasar. Agudeza y arte de ingenio, ed de Santos Alonso, en Obras completas, Madrid, Cátedra, 2011, pp. 431-808.

Gumbrecht, Hans Ulrich. Después de 1945. La latencia como origen del presente, Ciudad de México, Uia, 2015.

- Eine Geschichte der spanischen Literatur, Fráncfort del Meno, Suhrkamp,1991.

Krauss, Werner. La doctrina de la vida según Baltasar Gracián, tr. de Ricardo Estarriol, Madrid, Ed. Rialp, 1962.

Lethen, Helmut. Im reißenden Strom der Translationen. Der Gracián-Kick im 20. Jahrhundert. En <https://www.komparatistik-online.de/index.php/ komparatistik_online/article/view/131>.

- Suche nach dem Handorakel. Ein Bericht. Göttingen, Wallstein Verlag, 2012.

- Verhaltenslehren der Kälte. Lebensversuche zwischen den Weltkriegen, Fráncfort del Meno, Edition Suhrkamp, 1994.

Neumeister, Sebastian. "Prólogo", en Arthur Schopenhauer, Handorakels und Kunst der Weltklugheit, nueva ed rev. de la tr., Stuttgart, 2013, pp. $\mathrm{XV}$-XXX.

Nietzsche, Friedrich. U II 3. Otoño de 1873-Invierno de 1873-1874 (30), en Fragmentos póstumos, vol. I: 1869-1874, ed. dirigida por Diego Sánchez Meca, tr, intr. y notas de Luis E. de Santiago Cuervós, 2a. ed. corregida y aumentada, Madrid, Ed. Técnos, 2010.

Pawlita, Leonie. Staging Doubt. Skepticism in Early Modern European Drama, Berlín/Boston, Ed. de Gruyter, 2019.

von Koppenfels, Werner. Graciáns (Über)Lebensjahre, Nachwort zu Balthasar Gracián: Handorakel und Kunst der Weltklugheit, 4a. ed., Múnich, dtv Verlagsgesellschaft mbH \& Co. KG, 2013. 